\section{ATOMS AND ELECTRONS}

\section{Quantum Theory of Atomic Structure}

By Prof. John C. Slater. (International Series in Pure and Applied Physics.) Vol. 1. Pp. xii +502. 85s. 6d. Vol. 2. Pp. ix +439 . 101s. (New York: McGraw-Hill Book Company, Inc.; London : McGraw-Hill Publishing Company, Ltd., 1960.)

TN 1933, only seven years after the introduction of wave mechanics, Slater and Frank published their Introduction to Atomic Physics. They allotted 200 pages to atomic structure. But in 1951, when wave mechanics was just 25 years old, this material had grown to a complete book, Quantum Theory of Matter, with 500 pages. To-day, in 1961, Prof. Slater takes the first half of this second book, and expands it into two full volumes totalling nearly 1,000 pages. This is a striking indication of the almost catastrophic way in which our knowledge of this field has developed.

But the field itself has spread. Atomic theory is no longer the province of the spectroscopist measuring line frequencies and line widths. It plays a fundamental part in the totally new field of molecular structure, and its ideas have taken root in much of nuclear structure and the most exciting of all modern branches of theoretical physics-the solid state.

The subject is ripe for a major exposition. It seems likely that most of the main results and theories are now known. The advent of electronic computers has already influenced techniques. Much remains to be studied, but the methods of doing this are now fairly clear. It is entirely appropriate that Prof. Slater should write this monumental work. For during the past fifteen years his group at the Massachusetts Institute of Technology has studied atoms, molecules and solids with great success. We are now promised further books on these other topics. If they match the present ones in excellence they will be very welcome indeed.

Here is effectively everything that matters in the theory of atomic structure. It is set out in Slater's lively style (sometimes almost too colloquial), and with very great assurance. Reading these volumes is like watching a first-class chess player march irresistibly to his object. There is complete mastery of the material, much of which is his own, and a complete certainty about its ordering.

The first volume starts with 160 pages recapitulating elementary wave mechanies. Despite the author's claim, I do not feel that this is suitable for a beginner: it is inevitably compressed. But it is excellent for a student who already has some knowledge. Then follow accounts of the hydrogen atom, self-consistent-field, angular momentum, multiplet structure, with application in the iron group, and a series of some twenty appendixes elaborating points inadequately covered before. This material is enough to understand the main lines of thought, but not sufficient to start research.

Volume 2 starts with Hartree-Fock theory, and then goes on to group theory, angular momentum operators, Racah's method for complex spectra, the Dirac theory, magnetic properties of complex atoms, transition probabilities and hyperfine structure. It contains a wonderful set of tables, and carrios the subject right up to the present day. Both volumes are enriched with a series of bibliographies that greatly enhance their value.
Comparison is inevitable with Condon and Shortley's Theory of Atomic Spectra. In Slater there is much less direct comparison with experimental data, and more 'drive' towards the basic theory: there is almost nothing about $j j$-coupling (this is a pity) and isotope effects, or about polarizability and Stark effects. But there is the first full-scale development of Racah's work, the use of projection operators, the Fermi hole, nuclear quadruple effects, none of which is found in Condon and Shortley's book. Numerical techniques are also more advanced, and the whole outlook is more modern.

No one can expect to be entirely satisfied. But I found only one minor mistaks. I could have wished for more reference to the Thomas-Fermi statistical method, and a better account of Hund's rules (Hund does not get quite his share of credit). I also wish that the Rydberg unit of energy had been replaced by the atomic unit, so that a selfconsistent set of units could be used. But these are relatively trivial. Here-without any doubt at all-is a definitive account of atomic structure. It is a magnificent work, which no one but slater could have written : and it is beautifully published.

\section{A. Coulson}

\section{PROBLEMS OF ECONOMIC AND SOCIAL DEVELOPMENT}

Jamaica, 1830-1930

A Study in Economic Growth. By Gisela Eisner. Pp. xxiii + 399. (Manchester : The University Press, 1961.) 50s, net.

7 HE publication of this work can be welcomed without reservation by all who are interested in the problem of economic and social development. The investigations on which it is based were initiated and guided by Dr. Arthur Lewis, when professor of economics in the University of Manchester, and it thus provides evidence of the growing sense of responsibility of the new West Indian middle classes for the welfare of their communities. The project is as ably conceived as it is brilliantly executed.

Our knowledge of economic growth and social change has hitherto been severely restricted by the scarcity of accurate studies of the history of the societies which have been subject to the most rapid development over the past century. Here is one more, and a very good one, to add to our small collection. The author has extended her work over a wide field; she has thus been able to show how economic growth and organization have been interrelated with the social structure and social history of Jamaica. The result is to give the book a much wider interest than a more restricted study of economic statistics and economic trends would possess.

It would have been even more helpful if the period covered could have been extended to 1943, a year in which an elaborate census provided much material which could have been used for purposes of general comparison with the situation which prevails to-day. Even though the data were somewhat affected at that time by the impact of the Second World War, this was not so important as might be supposed; the influence on economic and social life of the postwar period of planned economic divelopment has been made more profound. It is probable, therefore, 